\title{
Matricellular proteins: an overview
}

\author{
Paul Bornstein
}

Received: 31 August 2009 /Accepted: 9 September 2009 /Published online: 25 September 2009

(C) The Author(s) 2009. This article is published with open access at Springerlink.com

Matricellular proteins are secreted into the extracellular environment, or matrix, but do not play a primary structural role in this location. Rather, these proteins modulate cell function by interacting with cell-surface receptors, proteases, hormones, and other bioeffector molecules, as well as with structural matrix proteins such as collagens. The term 'matricellular' was introduced to explain the unusual diversity of functions that were beginning to be recognized in proteins such as thrombospondin-1(TSP-1), SPARC, and tenascin-C. (Sage and Bornstein 1991; Bornstein 1995). The intent of segregating this subclass of secreted proteins was to emphasize that the extracellular environment was a major factor in regulating their synthesis, a process that had been termed 'dynamic reciprocity' at an earlier date (Bornstein et al. 1982). A review that summarized many of the considerations that led to the concept of matricellular proteins was published in Methods in Cell Biology (Bornstein 2002).

In additional reviews (Bornstein 2001; Bornstein and Sage 2002) some of the distinguishing characteristics of matricellular proteins were summarized in greater detail. These included: 1) high levels of expression during development and in response to injury; 2) binding to many cell-surface receptors, components of the extracellular matrix, growth factors, cytokines, and proteases; 3 ) induction of de-adhesion or counter-adhesion in contrast to the adhesivity of most matrix proteins (Murphy-Ullrich 2001; Liu et al. 2009), and 4) a grossly normal or subtle phenotype that is observed in mice with a targeted disruption

\section{P. Bornstein $(\square)$}

Departments of Biochemistry and Medicine,

University of Washington,

P.O. Box 219, Tesuque, NM 87574, USA

e-mail: bornsten@u.washington.edu (knockout) of some matricellular protein genes. The complexity of the functions of most matricellular proteins results from the fact that these functions are, in large part, contextual, i.e. they derive from the different structural proteins, cellsurface receptors, proteases, and cytokines with which these proteins come in contact in the local environment of different tissues.

The unexpected phenotypes of some matricellular protein-null mice have provided clues to the functions of matricellular proteins. Thus, for example, the abnormally shaped and sized collagen fibrils observed in TSP-2-null mice in skin and other connective tissues led to the demonstration that TSP-2 functions as a clearance factor for MMP2 in the pericellular environment (Yang et al. 2001). In turn, the elevated MMP2 levels in the pericellular environment of TSP2-null mice reduced tissue transglutaminase activity and the collagen crosslinks generated by this enzyme (Agah et al. 2005). As another example, the cataracts and increased adipogenesis encountered in SPARC-null mice led to a better understanding of extracellular matrix assembly (Brekken and Sage 2000) and SPARC signaling pathways (Nie and Sage 2009).

Although a useful review of the functions of a limited number of matricellular proteins in bone biology has been published (Alford and Hankenson 2006), and Sangaletti and Colombo (2008) have surveyed the functions of matricellular proteins in inflammation and cancer, this issue of the JCCS provides a more comprehensive coverage of the field and takes advantage of recent mechanistic information that improves our understanding of how matricellular proteins function.

Thus, for TSPs, Bornstein has described the mechanisms that enable TSP-1 and TSP-2 to function as both angiogenic and anti-angiogenic proteins, and the potential clinical applications of these properties; Hankenson and Delany 
consider the roles of TSP-2 and SPARC in bone formation; Lawler describes the effects of TSPs on the structure of the extracellular matrix; MacLauchlan and Kyriakides review the role of TSPs in wound healing, ischemia, and the foreign body response; and Schellings et al. review the roles of TSPs in cardiac remodeling.

For SPARC and members of the SPARC family, Bradshaw discusses the role of SPARC in extracellular matrix assembly; Arnold and Brekken consider the role of SPARC as a regulator of tumorigenesis, and Nie and Sage summarize the evidence for SPARC as an inhibitor of adipogenesis.

Some matricellar proteins are represented by single presentations. Lund et al. present the role of osteopontin in inflammatory proceses; Midwood and Orend consider the role of tenascin- $\mathrm{C}$ in tissue injury and tumorigenesis; Norris et al. describe the many facets of the effects of periostin on cardiac development, remodeling, and pathophysiology ; Merline et al. present evidence for the matricellular functions of small leucine-rich proteoglycans (SLRPS), and Yanagisawa et al. present data supporting the inclusion of fibulin-5 in the matricellular protein family. Finally, Eroglu summarizes the evidence for the roles of matricellular proteins in the development and function of the nervous system.

Clearly, the articles mentioned above do not cover all the proteins that are now considered to be matricellular. Prominent among those not included in this review are several members of the CCN (Cyr-61, Connective tissue growth factor, and Nov family of proteins that were recently reviewed (Chen and Lau 2009; Holburn et al. 2008; and Yeger and Perbal 2007), tenascin- X (Zweers et al. 2004), the galectins (Elola et al. 2007), plasminogen activator inhibitor type 1 (PAI-1) (Maquerlot et al. 2006), and autotaxin (Dennis et al. 2008).

An issue that has not been addressed in the categorization of matricellular proteins is whether to include matrix proteins, the matricellular function of which, as defined above, is revealed only when fragments of the proteins are investigated. It is now commonly recognized that new functions, not present in the intact protein, can be generated by limited physiological proteolysis (Sage 1997; Davis et al. 2000). However, it would seem preferable at this time, in the interest of brevity, to limit our discussion to matrix proteins with matricellular properties that are expressed in the intact proteins.

A PubMed search of the literature, performed at the end of the 2008 calendar year, revealed that there were 348 publications that used the term 'matricellular' in the title and/or abstract since its first use in 1995. The increase in recent years has been almost exponential, with 65 citations listed during 2008. A number of these citations concern proteins with credentials as matricellular proteins that are incomplete or questionable, but it is reasonable to expect that the list of matricellular proteins will grow as more information is gathered about other extracellular proteins with non-structural functions.

Open Access This article is distributed under the terms of the Creative Commons Attribution Noncommercial License which permits any noncommercial use, distribution, and reproduction in any medium, provided the original author(s) and source are credited.

\section{References}

Agah A, Kyriakides TR, Bornstein P (2005) Proteolysis of cell-surface tissue transglutaminase by matrix metallooproteinase- 2 contributes to the adhesive defect and matrix abnormalities in thrombospondin2-null fibroblasts and mice. Am J Path 167:81-88

Alford AI, Hankenson KD (2006) Matricellular proteins: extracellular modulators of bone development, remodeling, and regeneration. Bone 38:749-757

Bornstein P (1995) Diversity of function is inherent in matricellular proteins: an appraisal of thrombospondin1. J Cell Biol 130:503-506

Bornstein P (2001) Thrombospondins as matricellular modulators of cell function. J Clin Invest 107:929-934

Bornstein P (2002) Cell-matrix interactions: the view from the outside. Meth in Cell Biol 69:7-11

Bornstein P, Sage EH (2002) Matricellular proteins: extracellular modulators of cell function. Current Opin Cell Biol 14:608-616

Bornstein P, McPherson J, Sage EH (1982) Synthesis and secretion of structural macromolecules by endothelial cells in culture. In: Nossel HL, Vogel HJ (eds) Pathobiology of the Endothelial Cell, P\&S Biomedical Sciences Symposia Vol. 6. pp 215-228

Brekken RA, Sage EH (2000) SPARC, a matricellular protein at the crossroads of cell- matrix communication. Matrix Biol 19:569-580

Chen C-C, Lau LF (2009) Functions and mechanisms of action of CCN matricellular proteins. Int J Biochem Cell Biol 41:771-783

Davis GE, Bayless KJ, Davis MJ, Meinenger GA (2000) Regulation of tissue injury responses by the exposure of matricryptic sites within extracellular matrix macromolecules. Amer J Path 156:14891488

Dennis J, White MA, Forrest AD, Yuelling LM, Nogaroli L, Sfshari FS, Fox MA, Fuss B (2008) Phosphodiesterase-1 $\alpha$ /autotaxin's MORFO domain regulates oligodendroglial process network formation and focal adhesion organization. Mol Cell Neurosci 37:412-424

Elola MT, Wolfenstein-Todel C, Troncoso MF, Vasta GR, Rabinovich GA (2007) Galectins: matricellular glycan-binding proteins linking cell adhesion, migration and survival. Cell Mol Life Sci 13:16791700

Holburn KP, Acharya KR, Perbal B (2008) The CCN family of proteins: structure-function relationships. Trends Biochem Sci 33:461-473

Liu A, Mosher DF, Murphy-Ullrich JE, Goldblum SE (2009) The counteradhesive proteins, thrombospondin 1 and SPARC/ osteonectin, open the tyrosine phosphorylation-responsive paracellular pathway in pulmonary vascular endothelia. Microvascular Res 77:13-20

Maquerlot F, Galiacy S, Malo M, Guignabert C, Lawrence DA, d'Ortho M-P, Barlovatz-Meimon G (2006) Dual role for plasminogen activator inhibitor type 1 as soluble and as matricellular regulator of epithelial alveolar cell wound healing. Amer J Path 109:1624 1632 
Murphy-Ullrich JE (2001) The deadhesive activity of matricellular proteins: is intermediate cell adhesion an adaptive state? J Clin Invest 10:785-790

Nie J, Sage EH (2009) SPARC inhibits adipogenesis by its enhancement of $\beta$-catenin signaling. J Biol Chem 284:1279-1290

Sage EH (1997) Pieces of eight: bioactive fragments of extracellular proteins as regulators of angiogenesis. Trends Cell Biol 7:182-186

Sage EH, Bornstein P (1991) Minireview: extracellular proteins that modulate cell-matrix interactions: SPARC, tenascin, and thrombospondin. J Biol Chem 266:14831-14834
Sangaletti S, Colombo MP (2008) Matricellular proteins at the crossroad of inflammation and cancer. Cancer Lett 267:245-253

Yang Z, Strickland DK, Bornstein P (2001) Extracellular MMP2 levels are regulated by the LRP scavenger receptor and thrombospondin 2 . J Biol Chem 276:8403-8408

Yeger H, Perbal B (2007) The CCN family of genes: a perspective on CCN biology and therapeutic potential. J Cell Commun Signal 1:159-164

Zweers MC, Hakim AJ, Grahame R, Schalkwiik J (2004) Joint hypermobility syndromes: the physiologic role of tenascin-X gene defects. Arthritis Rheum 50:274-279 